http://jmscr.igmpublication.org/home/

ISSN (e)-2347-176x ISSN (p) 2455-0450

crossref DOI: https://dx.doi.org/10.18535/jmscr/v7i11.101

Journal Of Medical Science And Clinical Research

IGM Publication

An Official Publication of IGM Publication

\title{
Study of Post-operative Surgical Site Infection in Patients of Emergency Laparotomyin Tertiary hospital
}

\author{
Authors \\ Dr S B Ratnakishore MS ${ }^{1}$, Dr Paila Bhagya Sri ${ }^{2}$, Dr Dumpala Lalitha Kumara ${ }^{3}$, \\ Dr Lakshmi Prasanna ${ }^{4}$, Dr Tagore ${ }^{5}$ \\ ${ }^{1}$ Asst Professor of General Surgery Department, KGH, \\ ${ }^{2}$ Post Graduate of General Surgery Department, KGH, ${ }^{3}$ Post Graduate of General Surgery Dept, KGH \\ ${ }^{4}$ Post Graduate of General Surgery, KGH, ${ }^{5}$ Post Graduate of General Surgery, UGH
}

\begin{abstract}
Introduction: Surgical site infection classified as Major SSI and minor SSI. A major SSI is defined as a wound that either discharges significant quantities of pus spontaneously or needs a secondary procedure to drain it and with systemic signs such as tachycardia, pyrexiaand raised white cell count. Minor SSI may discharge pus or infected serous fluid but are not associated with excessive discomfort, systemic signs or delay in return home.

Aims and Objective: a) To study course of post operative surgical site infection in emergency laparotomy. Materials and Methods: Prospective observational study conducted in KGH vishakapatnam from Nov 2018 to July 2019

Results: SSI was observed in 239 patients out of 311, male are more affected than female. Patient with Surgical site infection increases hospital stay and morbidity. Patient associated with anemia has increase risk of developing Surgical site infection.

Conclusions: Surgical site infection increase the morbidity and hospital stay. There should be much more effort to decrease the incidence of Surgical site infection.
\end{abstract}

\section{Introduction}

The term surgical site infections (SSIs) means post-operative wound infection and is defined as that infection presenting up to 30 days after a surgical procedure if no prosthetic is placed and up to 1 year if a prosthetic is implanted in the patient.SSI remains a major limiter of surgical horizons inspite of advances. Nosocomial infections third most frequently accounting for nearly $20 \%$ among hospital in patients.

Noscomial infection has high incidence in surgery department where accumulating evidence suggests advances have been made in infection control practices, including improved operating room ventilation, sterilization methods, barriers, surgical techniques, and availability of antimicrobial prophylaxis. In emergency surgery the risk of infection is greater in all categories. The risk of wound infection is effected by the degree of contamination and also by multiple risk factors include diabetes mellitus, hypoxemia, hypothermia, immunosuppressive agents, and malnutrition.

SSIs results in increased morbidity, mortality, and do have a major impact on the cost of healthcare. The primary objectives of this study were to 
describe the incidence and risk factors associated with SSI in patients undergoing emergency laparotomy. The secondary objectives were to study the microbiological pattern of SSI in our population and their antibiotic sensitivity, and to study the effect of SSI on postoperative length of stay.

\section{Materials and Methods \\ Study Design and Participants}

We conducted a prospective observational study at King George hospital Vishakapatnam Andhra Pradesh. The target population consisted of all patients aged 14 years or more undergoing emergency laparotomy from Nov1 2018 to July 31, 2019. We excluded patients who left the operating theatre with an open packed wound or with a vacuum-assisted dressing.

Wound infection was diagnosed if any one of these criteria was fulfilled: Serous or nonpurulent discharge from the wound, pus discharge from the wound, the wound with the sign of inflammation and when wound was opened by the surgeon due to the localized collection. Swabs from the infected wound site were collected and sent for cultures and antibiotic sensitivity. Percentage of relevant data was calculated and studied. Ethics approval was obtained from the institutional review board.

\section{Data Collection}

1) Variables included in the analysis were patient preoperative risk factors (diabetes mellitus, immunosuppression,) smoking status, body mass index, demographic characteristics and preoperative hemoglobin and albumin levels.

2) Operative variables included type of surgery performed, duration of surgery, use of prophylactic antibiotic, wound contamination class, and drain use.

3) Outcome measures studied in addition to wound infection included admission to the intensive care unit, length of stay, postoperative complications and death.
Wound assessment was done with the Centres for Disease Control and Prevention and National Healthcare Safety Network definition of SSI (table 1) in patient whom follow up was done for 30days in ward, op, or through telephonic interview. The results of culture and antimicrobial sensitivity were included.

Table 1

\begin{tabular}{|c|c|}
\hline \multicolumn{2}{|c|}{ Surgical site infection classification according to the Centers for Disease } \\
\hline Superficial incisional SSI & Deep incisional SSI \\
\hline Occurs within $30 \mathrm{~d}$ & Occurs within $30 \mathrm{~d}$ \\
\hline Only skin and subcutaneous tissue & Deep soft tissues (fascial and muscle layers) \\
\hline $\begin{array}{l}\text { Patient has at least } 1 \text { of the } \\
\text { following: }\end{array}$ & $\begin{array}{l}\text { Patient has at least } 1 \text { of the following: } \\
\text { a. Purulent drainage from deep incision }\end{array}$ \\
\hline $\begin{array}{l}\text { a. Purulent drainage from } \\
\text { incision }\end{array}$ & $\begin{array}{l}\text { b. An incision that spontaneously } \\
\text { dehisces or is deliberately opened or }\end{array}$ \\
\hline $\begin{array}{l}\text { b. Organisms identified from } \\
\text { wound }\end{array}$ & $\begin{array}{l}\text { aspirated by surgeon, with or without } \\
\text { culture }\end{array}$ \\
\hline $\begin{array}{l}\text { c. Superficial incision that is } \\
\text { deliberately opened by } \\
\text { surgeon } \\
\text { d. Diagnosis of SSI by surgeon }\end{array}$ & $\begin{array}{l}\text { c. Abscess or other evidence of infection } \\
\text { that is detected on gross anatomic or } \\
\text { histopathologic examination, or } \\
\text { imaging }\end{array}$ \\
\hline $\begin{array}{l}\text { And patient has at least } 1 \text { of the } \\
\text { following: pain or tenderness, } \\
\text { localized swelling, erythema or heat }\end{array}$ & $\begin{array}{l}\text { And patient has at least } 1 \text { of the following: } \\
\text { fever (temperature }>38^{\circ} \mathrm{C} \text { ), localized pain or } \\
\text { tenderness }\end{array}$ \\
\hline
\end{tabular}

SSI $=$ surgical site infection

\section{Statistical analysis}

All values are multiplied by 100 to get percentages. The data was tabulated in Microsoft excel. Data analysis was done using SPSS.

\section{Results}

In total 311 patient out of which 146 are males and 93 are females $(\mathrm{M}: \mathrm{F}=2: 1)$. Their ages were between 14 to 85 years with mean age of $35.66+/-$ 12.57 years. The pre-operative hemoglobin concentration of the patients was $3.2-15.3 \mathrm{~g} / \mathrm{dl}$ (mean $10.29 \pm 1.71 \mathrm{~g} / \mathrm{dl})$. A total of $102(40.8 \%)$ patients had pre-operative anemia with hemoglobin concentration $<10 \mathrm{~g} / \mathrm{dl}$.

Relationship between age group and incidence of surgical site infection 


\section{JMSCR Vol||07||Issue||11||Page 578-584||November}

Regarding age group patients of age group 31-50

$(42.7 \%)$

years were more prone to wound infections

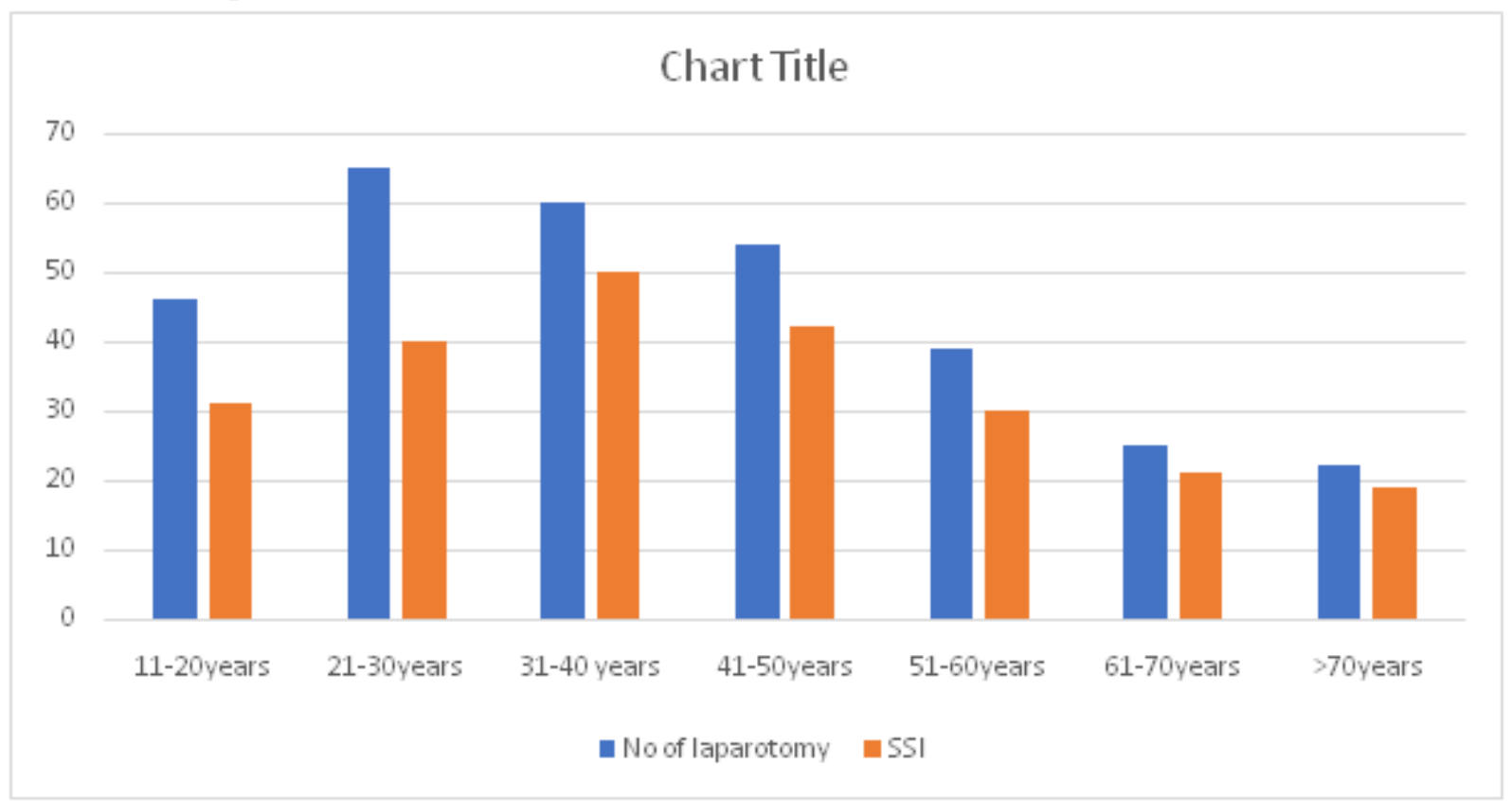

Out of 311 patients with emergency abdominal operations, the rate of SSI in different operations was observed. The highest rate of SSI $(50.1 \%)$ was in laparotomy with ileostomy for ileal perforation and appendicular perforation.

\section{Chart Title}

350

300

250

200

150

100

50

0

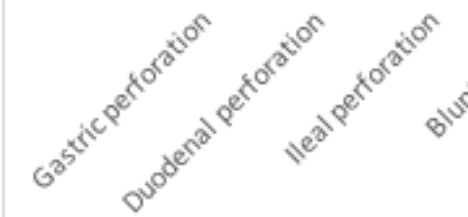

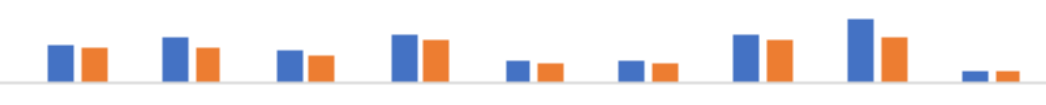
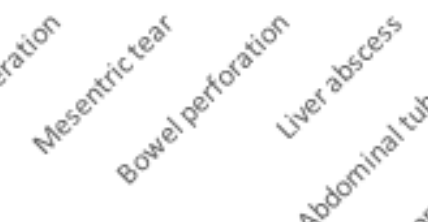

- No of cases $\quad$ SSI present 


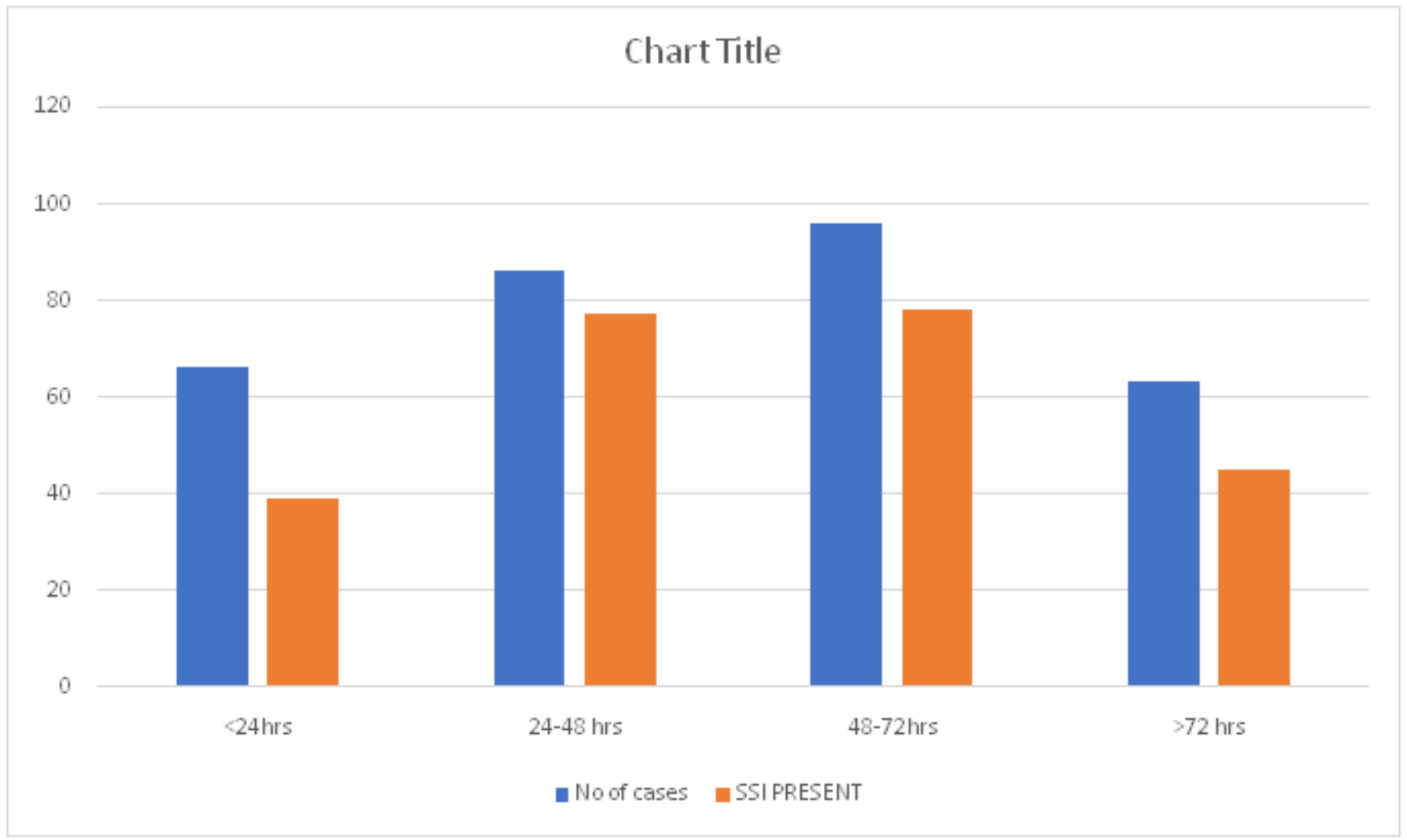

With regard to association between delay to initiate operation and rate of SSI it was observed that rate of infection increased as the time lapse between the appearance of first symptom and initiation of operation was increased.

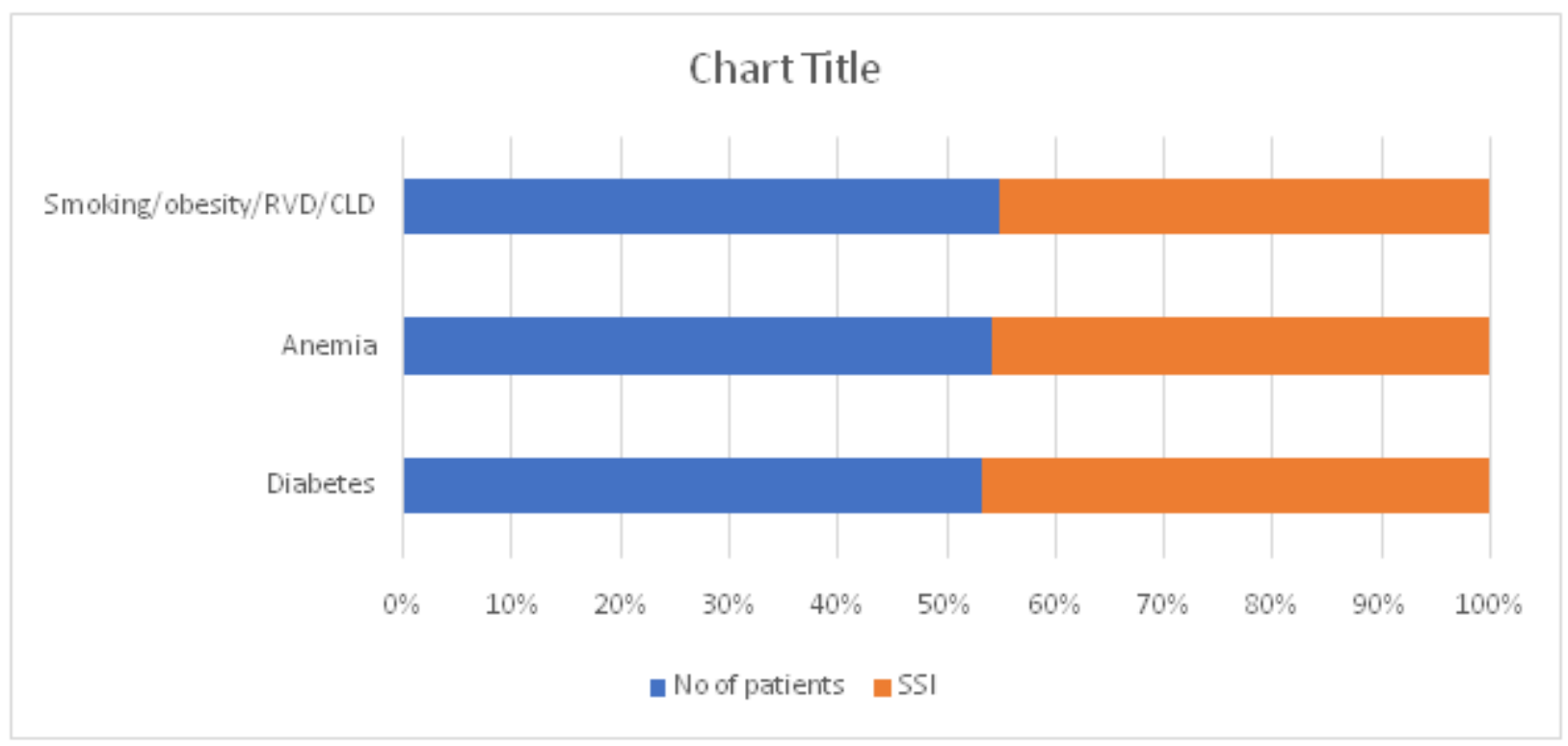

In relation to comorbidity, it was observed that 159patients had comorbid disorders associated with the main surgical disease and 152 patients had no comorbid disorder. Among the patients with comorbid disorders 146(91.8) developed SSI.
SSI was clinically diagnosed in 239 patients giving a incidence rate of $76.8 \%$. Of which $169(69.03 \%)$ were superficial SSI while 74(30.9\%) were deep SSI. Of which $186(77.8 \%)$ diagnosed on postoperative day3, 55(23\%) 
diagnosed on postoperative day 5 and 18 (7.5) diagnosed on postoperative day 7.Of which $179(74.8)$ resolved by the $9-11^{\text {th }}$ day, while remaining resolved by the $15-17^{\text {th }}$ day.

Multiple samples of discharge/pus from the wounds were sent for culture and sensitivity test. Escherichia coli were found as the most common organism (129 among 239 cases) causing 53.9\% of the surgical site infection.

Bacterial isolates obtained from samples of SSI $(n=239)$

\begin{tabular}{|l|c|}
\hline Bacteria & $\mathrm{n} \%$ \\
\hline Escherichia coli & 129 \\
\hline Staphylococcus aureus* & 36 \\
\hline Pseudomonas aeruginosa & 46 \\
\hline Klebsiella & 28 \\
\hline
\end{tabular}

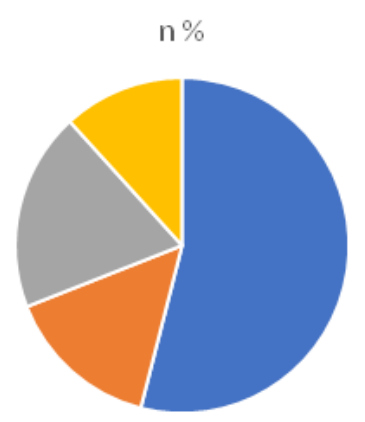

- Escherichia coli " Staphylococcus aureus* |- Pseudomonas aeruginosa "| Klebsiella

\section{Discussion}

The emergency laparotomy for acute abdomen is a major challenge for a surgeon. Post-operative care and pre-operative preparations is important for a successful outcome. Deficient care in either may produce unsatisfactory results irrespective of the standard of surgery. Post-operative SSI is the second most common type of adverse effect occurring in hospitalized patients following surgery and one of the most important causes of increased stay in hospital in surgically treated patients.

SSI surveillance is very important to hospital infection control and quality improvement programs, with feedback of SSI rates being an integral component of SSI reduction strategies. The incidence of SSI varies widely from hospital to hospital and also from one geographic location to anotherthese patients incur a higher cost because of increased days of hospitalizations, more post operative care, potential readmission to the hospital, and further surgical management.

As documented in the previous literature, in our study overall rate of SSI was $76.8 \%$ which is higher. Whereas other literature of Rajesh K. abbey $25.43 \%,{ }^{[13]}$ Satyanarayan $25.2 \%$, and Murtaza et al. $21.6 \%$ but noted higher $(38.1 \%)$ in the study of Adejumo et al. It was observed that rate of SSI in different age groups it was highest $58.9 \%$ in the literature of study done by Adejumo et al.

In the 31-50 years age group in our study it was $42.8 \%$. Regarding sex distribution of the, among the total 311 patients male was more prone to infection as compared to female which was same as other studies with different values.

It was observed that host factors such as type of disease, presence/absence

of comorbidity, and types of comorbidity, and other factors such as delay to initiate operation and duration of surgery were associated with the rate of SSI. The highest rate of infection (50.1) was in case of ileostomy done and appendicular perforation.

The rate of SSI increased as the time lapse between first manifestation of symptoms and initiation of operation SSI, it was observed that the SSI rate was $19.9 \%, 28.9 \%, 42.7 \%$, and $70.2 \%$ when operation was initiated $<24 \mathrm{~h}, 24-48 \mathrm{~h}, 48$ $72 \mathrm{~h}$, and $>72 \mathrm{~h}$, respectively. With different values, result was same as other studies in which infection rate was higher with time duration increases between unset of symptoms and operation. The rate of SSI increased statistically very significantly with that of the duration of the operation. Previous studies have also assessed the influence of prolonged operative time as a risk factor for SSI.

In relation to the appearance of infection, it was observed that most of the infections. $186(77.8 \%)$ diagnosed on postoperative day3, 55(23\%) diagnosed on postoperative day 5 and 18 (7.5) diagnosed on postoperative day 7.Of which 
$179(74.8)$ resolved by the $9-11^{\text {th }}$ day, while remaining resolved by the $15-17^{\text {th }}$ day.

In relation to comorbidity, it was observed that 80 patients had diabetes, 102 anemia and 80 patient had other comorbid disorders like smoking, CVA, CAD etc associated with the main surgical disease percentage of SSI was higher in a diabetic patient (45\%) when compared with a patient with no comorbid condition SSI was higher in associated with the comorbid condition Smoking delays the healing of SSIs by causing local and systemic vasoconstriction. This results in tissue hypoxia and hypovolemia.

As documented in previous studies severely anemic patients had the highest risk of getting SSI. A low hemoglobin concentration creates the risk of SSI by tissue hypoxia and impairment to tissue healing.

Out of 239 patients 129 showed growth of microorganism E. coli was found in $53.9 \%$ cases. Staphylococcus aureus was causing $24.2 \%$. These are supported by the findings of a study conducted by Sultan et al. in 2007.

For the prevention of SSI antibiotics such as ceftriaxone, piperacillin- tazobactam, ciprofloxcin, and metronidazole was used in pre-operative and post-operative period in all of the cases

\section{Conclusion}

SSI is leading cause of post-operative morbidity and increased hospital stay. Still proper surveillance to be conducted to control the rate of Surgical site infection. Improper antibiotic usage to be decreased to decrease the resistance rate.

\section{References}

1. Horan TC, Andrus M, Dudeck MA. CDC/NHSN surveillance definition of health care-associated infection and criteria for specific types of infections in the acute care setting. Am J Infect Control. 2008;36:309-32. [PubMed] [Google Scholar]

2. Azoury S, Farrow $\mathrm{N}, \mathrm{Hu} \mathrm{Q}$, et al. Postoperative abdominal wound infection epidemiology, risk factors, identification, and management. Chron Wound Care Manage Res. 2015;2:137-48. [Google Scholar]

3. Aga E, Keinan-Boker L, Eithan A, et al. Surgical site infections after abdominal surgery: incidence and risk factors. A prospective cohort study. Infect Dis (Lond) 2015;47:761-7. [PubMed] [Google Scholar]

4. Chauhan S, Chauhan B, Sharma H. Assessment of post- operative complications in emergency abdominal surgery in a tertiary care centre. Sch J App Med Sci 2017;5:1581-7.

5. Driscoll P, Farmery AD, Bulstrode CJK. Postoperative care. In: Russel RC, Williams NS, Bulstrode CJ, editors. Bailey \& Love's Short Practice of Surgery. 24th ed. New York: Oxford University Press; 2004. p. 1436-49.

6. Lubega A. Incidence and etiology of surgical site infections among emergency postoperative patients in Mbarara regional referral hospital, South Western Uganda. Surg Res Pract 2017;2017. Article ID: 6365172, 6.

7. Burke JP. Infection control: A problem for patient safety. N Engl J Med 2003; 348:651-6.

8. Liau KH, Aung KT, Chua N, Ho CK, Chan CY, Kow A, et al. Outcome of a strategy to reduce surgical site infection in a tertiary-care hospital. Surg Infect (Larchmt) 2010;11:151-9.

9. Anderson DJ. Surgical site infections. Infect Dis Clin North Am 2011;25:135-53.

10. Maier S, Körner P, Diedrich S, Kramer A, Heidecke CD. Definition and management of wound infections. Chirurg 2011;82:23541.

11. Gaynes R, Richards C, Edwards J, Emori TG, Horan T, Alonso-Echanove J, et al. Feeding back surveillance data to prevent 
hospital-acquired infections. Emerg Infect Dis 2001;7:295-8.

12. Duque-Estrada EO, Duarte MR, Rodrigues DM, Raphael MD. Wound infections in pediatric surgery: A study of 575 patients in a university hospital. Pediatr Surg Int 2003;19:436-8.

13. Abbey RK, Mohan M, Malik N, Tiwari R, Nahar S. Surgical site infection in a rural teaching hospita of North India. Int $\mathbf{J}$ AdvInteg Med Sci 2017;2;11-6.

14. Satyanarayana V, Prashanth HV, Basavaraj B, Kavyashree AN. Study of surgical site infections in abdominal surgeries. J Clin Diag Res 2011;5:935-9.

15. Murtaza B, Saeed S, Sharif MA. Postoperative complications in emergency versus elective laparotomies at a peripheral hospital. J Ayub Med Coll Abbottabad 2010;22:42-7.

16. Adejumo AA, Nuhu M, Afolaranmi T. Incidence of and risk factors for abdominal surgical site infection in a Nigerian tertiary care centre. Int J Infect Control 2015;11:4.

17. Maheshwari MK. A prospective study of surgical site infection in elective and emergency abdominal surgery inCssh, Meerut. J Adv Res Biol Sci 2013;5:413-8.

18. Giri S, Kandel BP, Pant S, Lakhey PJ, Singh YP, Vaidya P, et al. Risk factors for surgical site infections in abdominal surgery:A study in Nepal. Surg Infect (Larchmt) 2013;14:313-8.

19. Mawalla B, Mshana SE, Chalya PL, Imirzalioglu C, Mahalu W. Predictors of surgical site infections among patients undergoing major surgery at Bugando Medical Centre in Northwestern Tanzania. BMC Surg 2011;11:21.
20. Ikeanyi UO, Chukwuka CN, Chukwuanukwu TO. Risk factors for surgical site infections following clean orthopaedic operations. Nigerian J ClinPract 2013;16:443-7.

21. Pomposelli JJ, Baxter JK 3rd, Babineau TJ, Pomfret EA, Driscoll DF, Forse RA, et al. Early postoperative glucose control predicts nosocomial infection rate in diabetic patients. JPEN J Parenter Enteral Nutr 1998;22:77-81.

22. Motie MR, Ansari M, Nasrollahi HR. Assessment of surgical site infection risk factors at imam Reza Hospital, Mashhad, Iran between 2006 and 2011. Med J Islamic Rep Iran 2006;28:52.

23. Sultan J, Bilal HB, Kiran H, Bilal BB, Yusuf A. Emergency abdominal surgery; Incidence of intra-abdominal sepsis and its management. Prof Med J 2007;14:10-6.

24. Rasul G, Ashraf SA. The role of routine antibiotic in the prevention of wound infection after surgery. BMRC Bull 1979;5:71-4. 